\title{
KEANEKARAGAMAN FAUNA TANAH \\ DI TAMAN NASIONAL BROMO TENGGER SEMERU SEBAGAI BIOINDIKATOR TANAH BERSULFUR TINGGI
}

\author{
Dwi Suheriyanto \\ Jurusan Biologi Fakultas Sains dan Teknologi \\ Universitas Islam Negeri (UIN) Maulana Malik Ibrahim Malang \\ Email: dsuheriyanto@yahoo.com
}

\begin{abstract}
The using of bioindikator lately become more important with the main function is to describe the existence of relevancy with biotic factor condition and abiotic area. Land fauna is enough as land indicator because it has sensitive respond to land and climate management practice, having good correlation to the land characteristic that benefits and the ecology function can describe causal chain that connects land management decision to the last productivity and plant and animal health. This research has purpose to identify kind of land fauna found in Bromo Tengger Semeru national park, analyse kinds of land fauna and analyse land fauna that can be used as land bioindikator with high sulphur standard.

The research uses exploration method, that arrange land fauna observation Bromo Tengger Semeru national park and taking land sample to be analyzed in laboratory. Taking sample location in Bromo, Jemplang area (near Bromo mountain). In each location is being observed to land fauna with plot 1 X 1 $m$, as many as 10 plots. Land fauna found in each plots is noted about genre and amount. The sample of the land is taken, then brought to the laboratory and analyzed to find out the content of $\mathrm{pH}$ land, $S$ land, organic material and $C / N$ land.

The result of this research shows that land fauna found in Bromo Tengger Semeru national park are 10 ordo, contained 29 family. Land fauna diversity in Bromo mountain is in lower area if it is compared with other area, with index 2.07 variety. Jemplang area has index variety 2.35 and Penanjakan area has index the highest fauna diversity, that is 2.73. Bromo mountain area has total sulphur 74,683 $\mathrm{mg} / 1000 \mathrm{~g}$ land and it is the area of research within highest sulphur. Land fauna used as land bioindicator within highest sulphur is ordo Brachyderinae for indicator the existence fauna and Mesoveliidae for bioindicator the inexistence of fauna.
\end{abstract}

Keywords: fauna, bioindikator, Sulfur, Bromo

\section{A. PENDAHULUAN}

Fauna tanah adalah fauna yang hidup di tanah, baik yang hidup di permukaan tanah maupun yang terdapat di dalam tanah. Fauna tanah merupakan salah satu komponen tanah. Kehidupan fauna tanah sangat tergantung pada habitatnya, karena keberadaan dan kepadatan populasi suatu jenis fauna tanah di suatu daerah sangat ditentukan oleh keadaan daerah tersebut. Dengan perkataan lain keberadaan dan kepadatan populasi suatu jenis fauna tanah di suatu daerah sangat tergantung dari faktor lingkungan 
yaitu lingkungan biotik dan lingkungan abiotik (Suin, 1997).

Fauna tanah merupakan salah satu kelompok heterotrof utama di dalam tanah. Proses dekomposisi dalam tanah tidak akan mampu berjalan cepat bila tidak ditunjang oleh kegiatan fauna tanah. Keberadaan fauna dalam tanah sangat tergantung pada ketersediaan energi dan sumber makanan untuk melangsungkan hidupnya, seperti bahan organik dan biomassa hidup yang semuanya berkaitan dengan aliran siklus karbon dalam tanah. Dengan ketersediaan energi dan hara bagi fauna tanah tersebut, maka perkembangan dan aktivitas fauna tanah akan berlangsung baik dan timbal baliknya akan memberikan dampak positif bagi kesuburan tanah.

Menurut Setiadi (1989), peranan terpenting dari fauna tanah di dalam ekosistem adalah sebagai perombak bahan organik. Nutrisi tanaman yang berasal dari berbagai residu tanaman akan mengalami proses dekomposisi sehingga terbentuk humus sebagai sumber nutrisi bagi tanah. Buckman dan Brady (1982) menambahkan bahwa fauna tanah berperan penting dalam mempercepat penyediaan hara dan juga sebagai sumber bahan organik tanah. Beberapa fauna tanah berperan langsung dalam menghancurkan fraksi-fraksi organik tanah.

Beare et al. (1995) menyatakan bahwa fauna tanah berpengaruh terhadap karakteristik fisik, kimia dan biologi tanah, dimana struktur komunitas biotik dapat mempengaruhi siklus biogeokimia yang terjadi di dalam tanah. Menurut Suhardjono (1997), keberadaan fauna tanah sangat dipengaruhi oleh faktor lingkungan, seperti suhu udara, suhu tanah dan $\mathrm{pH}$ tanah. Beberapa jenis fauna permukaan tanah dapat digunakan sebagai petunjuk (indikator) terhadap kesuburan tanah atau keadaan tanah. Shahabuddin (2003) menyatakan bahwa penggunaan bioindikator akhir-akhir ini dirasakan semakin penting dengan tujuan utama untuk menggambarkan adanya keterkaitan antara kondisi faktor biotik dan abiotik lingkungan.

Penggunaan bioindikator akhirakhir ini dirasakan semakin penting dengan tujuan utama untuk menggambarkan adanya keterkaitan dengan kondisi faktor biotik dan abiotik lingkungan. Menurut McGeoch (1998), bioindikator atau indikator ekologi adalah taksa atau kelompok organsime yang sensitif terhadap dan memperlihatkan gejala terpengaruh terhadap tekanan lingkungan akibat aktifitas manusia atau akibat kerusakan sistem biotik.

Fauna tanah cukup baik sebagai bioindikator tanah karena memiliki respon yang sensitif terhadap praktek pengelolaan lahan dan iklim, berkorelasi baik terhadap sifat tanah yang menguntungkan dan fungsi ekologis dapat menggambarkan rantai sebab-akibat yang menghubungkan keputusan pengelolaan lahan terhadap produktivitas akhir dan kesehatan tanaman dan hewan. Tetapi pengukuran organisme tanah memerlukan banyak kriteria supaya dapat digunakan sepenuhnya sebagai indikator pengelolaan lahan yang sesuai, termasuk kelimpahannya, keragaman, struktur jaringan dan stabilitas komunitas (Sarifuddin, 2004).

Suwondo dkk. (1996) menyatakan bahwa Acarina dan Collembola dapat dijadikan sebagai indikator tanah masam. Berdasarkan 
Keanekaragaman Fauna Tanah Di Taman ...

penelitian Suwondo (2002) pada lahan gambut diketahui bahwa ordo Collembola dan Hymenoptera menunjukkan proporsi yang tinggi pada permukaan tanah, sedangkan dalam tanah ordo Collembola dan Acarina menempati proporsi yang tinggi dibandingkan dengan ordo lainnya. Hasil penelitian Rahmawaty (2004) di Hutan Wisata Alam Sibolangit menunjukkan bahwa pada lahan berumput ditemukan famili Ixodidae, Tetranychidae dan Formicidae, sedangkan pada lahan hutan ditemukan famili Termitidae, Ixodidae dan Formicidae. Pada penelitian Rizali dkk., (2002) didapatkan predator Carabidae dan semut pada pematang sawah di Taman Nasional Gunung Halimun.

Taman Nasional Bromo Tengger Semeru mempunyai ciri khusus sebagai akibat dari keluarnya gas sulfur dari dalarn kawah gunung Bromo, sehingga kandungan sulfur dalam tanah lebih tinggi dibandingkan dengan daerah lain. Tipe ekosistemnya adalah submontana, montana dan sub-alphin dengan pohon-pohon yang besar dan berusia ratusan tahun. Beberapa jenis tumbuhan yang terdapat di Taman Nasional Bromo Tengger Semeru antara lain jamuju (Dacrycarpus imbricatus), cemara gunung (Casuarina sp.), eidelweis (Anaphalis javanica), berbagai jenis anggrek dan jenis rumput langka (Styphelia pungieus). Terdapat sekitar 137 jenis burung, 22 jenis mamalia dan 4 jenis reptilia di taman nasional ini. Satwa langka dan dilindungi yang terdapat di taman nasional ini antara lain luwak (Pardofelis marmorata), rusa (Cervus timorensis ), kera ekor panjang (Macaca fascicularis), kijang (Muntiacus muntjak), ayam hutan merah (Gallus gallus), macan tutul (Panthera pardus), ajag (Cuon alpinus) dan berbagai jenis burung seperti alap-alap burung (Accipiter virgatus ), rangkong (Buceros rhinoceros silvestris), elang ular bido (Spilornis cheela bido), srigunting hitam (Dicrurus macrocercus), elang bondol (Haliastur indus) dan belibis yang hidup di Ranu Pani, Ranu Regulo dan Ranu Kumbolo (Anonimous, 2009).

Beberapa penelitian Taman Nasional Bromo Tengger Semeru yang telah dipublikasikan adalah Survei Kupu-kupu (Rhopalocera: Lepidoptera) di Hutan Ireng-ireng Taman Nasional Bromo Tengger Semeru (Suharto dkk., 2005), dan Kajian Ekologi Tumbuhan Obat Langka di Taman Nasional Bromo Tengger Semeru (Hidayat dan Risna, 2007). Pada hutan konservasi perlu dilakukan deteksi dini terhadap setiap faktor biotik dan abiotik yang dalam jangka panjang akan mempengaruhi kesehatan dan vitalitas hutan dan faktor-faktor yang dapat mengindikasikan tingkat kerusakan hutan (Speight dan Wylie, 2001).

Penelitian bertujuan untuk mengidentifikasi berbagai jenis fauna tanah yang ditemukan di Taman Nasional Bromo Tengger Semeru, menganalisis keanekaragaman fauna tanah di Taman Nasional Bromo Tengger Semeru dan menganalisis fauna tanah yang dapat digunakan sebagai bioindikator tanah dengan kadar sulfur tinggi.

\section{B. BAHAN DAN METODE \\ 1. Bahan Penelitian:}

Bahan yang digunakan dalam penelitian ini adalah populasi fauna tanah di Taman Nasional Bromo 
Tengger Semeru dan bahan pengawet fauna.

\section{Metode Penelitian:}

a. Pertama-tama ditentukan 3 lokasi pengambilan sampel, yaitu daerah gunung Bromo, daerah Jemplang (dekat gunung Bromo) dan daerah Penanjakan (jauh dari gunung Bromo)

b. Pada masing-masing lokasi dilakukan pengamatan terhadap fauna tanah dengan menggunakan metode absolut, yaitu dengan mengadakan pengamatan langsung pada plot 1 $\mathrm{X} 1 \mathrm{~m}$.

c. Jumlah plot yang dibuat pada masing-masing lokasi adalah 10 plot.

d. Fauna tanah yang ditemukan pada masing-masing plot dicatat jenis dan jumlahnya.

e. Sampel fauna tanah dibawa ke laboratorium untuk didokumentasi dan diidentifikasi berdasarkan acuan Borror dkk. (1996).

f. Sampel tanah diambil secara acak pada 3 titik di masing-masing lokasi.

g. Sampel tanah dibawa ke laboratorium dan dianalisis untuk mengetahui kandungan $\mathrm{pH}$ tanah, kandungan $\mathrm{S}$ tanah, bahan organik tanah dan $\mathrm{C} / \mathrm{N}$ tanah.

\section{Analisis Data}

Tingkat keanekaragaman fauna tanah dianalisis dengan indeks keanekaragaman $\left(H^{\prime}\right)$ ShannonWeaver (Southwood, 1978), yaitu:

$$
H^{\prime}=-\sum p i \ln p i
$$

Keterangan :

H': indeks keanekaragaman ShannonWeaver

pi: proporsi spesies ke i di dalam sampel total
Fauna tanah yang berpotensi sebagai bioindikator ditentukan dengan melihat Indeks Nilai Pentingnya. Menurut Sugianto (1994) Indeks Nilai Penting dapat ditentukan dengan:

a. Frekuensi (F):

$$
F i=\frac{J i}{K}
$$

Keterangan:

$F i$ : Frekuensi relatif untuk spesies ke i

$J i$ : Jumlah plot yang terdapat spesies ke i

$K$ : Jumlah total plot yang dibuat

b. Frekuensi relatif $(\mathrm{Fr})$ :

$$
\begin{aligned}
& F r: \text { Frekuensi relatif spesies ke i } \\
& F i: \text { Frekuensi untuk spesies ke i } \\
& \Sigma F: \text { Jumlah total frekuensi untuk semua } \\
& \text { spesies }
\end{aligned}
$$$$
\text { Keterangan: }
$$$$
F r=\frac{F i}{\sum F} \quad \mathrm{X} \mathrm{100 \%}
$$

c. Kelimpahan $(\mathrm{K})$ :

$$
\mathrm{K}=\frac{n i}{A}
$$

Keterangan:

$K$ : Kelimpahan spesies untuk spesies ke i $n i$ : Jumlah total individu spesies ke $\mathrm{i}$

$A:$ Luas total daerah yang disampling

d. Kelimpahan relatif $(\mathrm{Kr})$ :

$$
K r=\frac{K i}{\sum K} \mathrm{X} 100 \%
$$

Keterangan:

$K r:$ Kelimpahan relatif spesies ke i

$K i$ : Kelimpahan untuk spesies ke i

$\Sigma K$ : Jumlah kelimpahan semua spesies

e. Indeks Nilai Penting (INP): INP = $\mathrm{Fr}+\mathrm{Kr}$ 
Keanekaragaman Fauna Tanah Di Taman ...

\section{HASIL DAN PEMBAHASAN}

Fauna tanah yang ditemukan dari lokasi penelitian dan telah diidentifikasi secara keseluruhan disajikan pada tabel berikut ini:

Tabel 1. Keanekaragaman fauna tanah pada beberapa daerah penelitian

\begin{tabular}{|c|c|c|c|c|c|}
\hline \multirow{2}{*}{ No. } & \multirow{2}{*}{ Ordo } & \multirow{2}{*}{ Famili } & \multicolumn{3}{|c|}{ Jumlah (individu) } \\
\hline & & & Bromo & Jemplang & Penanjakan \\
\hline 1. & Araneida & Oxyopidae 1 & - & - & 129 \\
\hline 2. & Araneida & Oxyopidae 2 & 26 & 34 & 24 \\
\hline 3. & Araneida & Linyphiidae 1 & 21 & 46 & 49 \\
\hline 4. & Araneida & Linyphiidae 2 & - & 20 & - \\
\hline 5. & Araneida & Salticidae 1 & - & - & 82 \\
\hline 6. & Araneida & Salticidae 2 & - & - & 37 \\
\hline 7. & Araneida & Salticidae 3 & 22 & - & - \\
\hline 8. & Araneida & Opiliones 1 & - & 20 & 36 \\
\hline 9. & Araneida & Opiliones 2 & - & 14 & 37 \\
\hline 10. & Araneida & Opiliones 3 & - & - & 26 \\
\hline 11. & Araneida & Araneidae 1 & 24 & 20 & 29 \\
\hline 12. & Araneida & Araneidae 2 & - & - & 49 \\
\hline 13. & Araneida & Lycosidae 1 & 33 & - & - \\
\hline 14. & Araneida & Lycosidae 2 & 26 & - & - \\
\hline 15. & Araneida & Lycosidae 3 & - & - & 45 \\
\hline 16. & Araneida & Thomisidae & 28 & - & - \\
\hline 17. & Blattaria & Blattellidae & - & 24 & - \\
\hline 18. & Coleoptera & Scarabaeidae & - & - & 112 \\
\hline 19. & Coleoptera & Lathriidae & - & 108 & 65 \\
\hline 20. & Coleoptera & Meloidae & - & 66 & 53 \\
\hline 21. & Coleoptera & Brachyderinae & 68 & - & - \\
\hline 22. & Diptera & Scapthophagidae & - & - & 114 \\
\hline 23. & Diptera & Tachinidae & 108 & 19 & - \\
\hline 24. & Hemiptera & Mesoveliidae & - & 182 & 89 \\
\hline 25. & Homoptera & Hecalinae & 141 & 103 & - \\
\hline 26. & Hymnoptera & Formicidae & 247 & 107 & 209 \\
\hline 27. & Neuroptera & Mantispidae & - & 13 & 27 \\
\hline 28. & Trichoptera & Limnephilidae & - & - & 21 \\
\hline \multirow[t]{3}{*}{29.} & Orthoptera & Acrididae & 25 & 17 & - \\
\hline & Total & & 769 & 793 & 1233 \\
\hline & \multicolumn{2}{|c|}{ Indeks keanekaragaman } & 2,07 & 2,35 & 2,73 \\
\hline
\end{tabular}

Barnes dkk., (1997) menyatakan bahwa fauna tanah adalah fauna yang memanfaatkan tanah sebagai habitat atau lingkungan yang mendukung aktifitas biologinya. Fauna tanah merupakan salah satu organisme penghuni tanah yang berperan sangat besar dalam perbaikan kesuburan tanah dengan menghancurkan fisik, pemecahan bahan menjadi humus, menggabungkan bahan yang membusuk pada lapisan tanah bagian atas, dan membentuk kemantapan agregat antara bahan organik dan bahan mineral tanah.
Fauna tanah yang diperoleh dari daerah Bromo ada 6 ordo, yang terbagi dalam 12 famili, Ordo yang banyak ditemukan di daerah Bromo adalah ordo Araneida, yaitu ada 7 famili. Jumlah fauna terbanyak ditemukan pada famili Formicidae. dari daerah Jemplang ada 8 ordo, yang terbagi dalam 15 famili, dan dari daerah Penanjakan ada 7 ordo, yang terbagi dalam 19 famili. Fauna tanah yang diperoleh dari daerah Jemplang ada 8 ordo, yang terbagi dalam 15 famili. Ordo yang banyak ditemukan di daerah Jemplang adalah 
ordo Araneida, yaitu ada 6 famili. Jumlah fauna terbanyak ditemukan pada famili Mesoveliidae. Fauna tanah yang diperoleh dari daerah Penanjakan ada 7 ordo, yang terbagi dalam 19 famili. Ordo yang banyak ditemukan di daerah Penanjakan adalah ordo Araneida, yaitu ada 11 famili. Jumlah fauna terbanyak ditemukan pada famili Formicidae.

Pengelompokan terhadap fauna tanah sangat beragam, mulai dari Protozoa, Rotifera, Nematoda, Annelida, Mollusca, Arthropoda, hingga Vertebrata. Fauna tanah dapat dikelompokkan atas dasar ukuran tubuhnya, kehadirannya di tanah, habitat yang dipilihnya dan kegiatan makannya. Berdasarkan kehadirannya, fauna tanah dibagi atas kelompok transien, temporer, periodik dan permanen. Berdasarkan habitatnya fauna tanah digolongkan menjadi golongan epigeon, hemiedafon dan eudafon. Fauna epigeon hidup pada lapisan tumbuh-tumbuhan di permukaan tanah, hemiedafon pada lapisan organik tanah, dan yang eudafon hidup pada tanah lapisan mineral. Berdasarkan kegiatan makannya fauna tanah ada yang bersifat herbivora, saprovora, fungivora dan predator (Suin, 1997).

Indeks keanekaragaman fauna di daerah Bromo paling rendah, hal ini kemungkinan disebabkan oleh rendahya $\mathrm{pH}$ tanah, bahan organik tanah dan rasio $\mathrm{C} / \mathrm{N}$ sedangkan total Sulfur tanah sangat tinggi (Tabel 2). Kondisi ini menyebabkan tumbuhan yang berperan sebagai produsen tidak mampu tumbuh dengan baik, sehingga fauna yang berada pada tingkat trofik yang lebih tinggi jumlahnya terbatas.

Tabel 2. Data fisik lingkungan pada beberapa daerah penelitian

\begin{tabular}{|c|c|c|c|c|c|c|c|}
\hline No. & Lokasi & pH & Total S (mg/1000 g) & BO & $(\%)$ & Rasio & $\mathrm{C} / \mathrm{N}$ \\
\hline 1. & Bromo & 5,20 & 74,683 & 2,316 & & 10,677 & \\
\hline 2. & Jemplang & 5,57 & 54,441 & 3,868 & & 15,433 & \\
\hline 3. & Penanjakan & 5,63 & 46,042 & 3,860 & & 12,547 & \\
\hline
\end{tabular}

Jemplang adalah daerah yang berada di dekat gunung Bromo. Dari hasil penelitian diketahui bahwa indeks keanekaragaman di daerah Jemplang lebih tinggi dibandingkan Bromo. Hal tersebut kemungkinan disebabkan karena daerah Jemplang mempunyai vegetasi yang lebih lebat dibandingkan Bromo, sehingga didapatkan fauna yang lebih banyak. Dari hasil analisis tanah diketahui bahwa ph tanahnya lebih tinggi dibandingkan Bromo, total Sulfur lebih rendah, sedangkan bahan organik tanah dan rasio $\mathrm{C} / \mathrm{N}$ di daerah Jemplang paling tinggi dibandingkan 2 daerah lainnya.

Penanjakan merupakan daerah yang lebih jauh dari Bromo, jika dibandingkan dengan Jemplang. Indeks keanekaragaman di daerah Penanjakan paling tinggi dibandingkan 2 daerah lainnya, hal ini kemungkinan disebabkan oleh kondisi fisik lingkungan daerah Penanjakan yang mempunyai $\mathrm{pH}$ tanah paling tinggi dibandingkan daerah lainnya dan total Sulfur paling rendah.

Tabel 3. Indeks Nilai Penting fauna tanah pada beberapa daerah penelitian

\begin{tabular}{llllll}
\hline \multirow{2}{*}{ No. } & \multirow{2}{*}{ Ordo } & \multirow{2}{*}{ Famili } & \multicolumn{2}{l}{ Indeks Nilai Penting (\%) } \\
\cline { 3 - 5 } & & Bromo & Jemplang & Penanjakan \\
\hline 1. & Araneida & Oxyopidae 1 & - & - & 15,34 \\
2. & Araneida & Oxyopidae 2 & 12,59 & 10,24 & 5,20 \\
3. & Araneida & Linyphiidae 1 & 10,63 & 12,94 & 9,67 \\
4. & Araneida & Linyphiidae 2 & - & 10,86 & -
\end{tabular}


Keanekaragaman Fauna Tanah Di Taman ...

\begin{tabular}{|c|c|c|c|c|c|}
\hline 5. & Araneida & Salticidae 1 & - & - & 12,34 \\
\hline 6. & Araneida & Salticidae 2 & - & - & 7,88 \\
\hline 7. & Araneida & Salticidae 3 & 10,76 & - & - \\
\hline 8. & Araneida & Opiliones 1 & - & 8,47 & 8,61 \\
\hline 9. & Araneida & Opiliones 2 & - & 6,53 & 8,69 \\
\hline 10. & Araneida & Opiliones 3 & - & - & 6,99 \\
\hline 11. & Araneida & Araneidae 1 & 12,33 & 9,66 & 7,23 \\
\hline 12. & Araneida & Araneidae 2 & - & - & 9,67 \\
\hline 13. & Araneida & Lycosidae 1 & 13,50 & - & - \\
\hline 14. & Araneida & Lycosidae 2 & 11,28 & - & - \\
\hline 15. & Araneida & Lycosidae 3 & - & - & 7,71 \\
\hline 16. & Araneida & Thomisidae & 11,54 & - & - \\
\hline 17. & Blattaria & Blattellidae & - & 11,36 & - \\
\hline 18. & Coleoptera & Scarabaeidae & - & - & 14,77 \\
\hline 19. & Coleoptera & Lathriidae & - & 21,95 & 9,34 \\
\hline 20. & Coleoptera & Meloidae & - & 15,47 & 9,18 \\
\hline 21. & Coleoptera & Brachyderinae & 14,11 & - & - \\
\hline 22. & Diptera & Scapthophagidae & - & - & 15,75 \\
\hline 23. & Diptera & Tachinidae & 23,25 & 8,35 & - \\
\hline 24. & Hemiptera & Mesoveliidae & - & 28,90 & 12,91 \\
\hline 25. & Homoptera & Hecalinae & 27,55 & 17,75 & - \\
\hline 26. & Hymnoptera & Formicidae & 41,33 & 21,83 & 24,27 \\
\hline 27. & Neuroptera & Mantispidae & - & 6,40 & 7,88 \\
\hline 28. & Trichoptera & Limnephilidae & - & - & 6,58 \\
\hline 29. & Orthoptera & Acrididae & 11,15 & 9,29 & - \\
\hline
\end{tabular}

Fauna tanah memainkan peranan yang sangat penting dalam perombakan zat atau bahan-bahan organik dengan cara menghancurkan jaringan secara fisik dan meningkatkan ketersediaan daerah bagi aktifitas bakteri dan jamur, melakukan perombakan pada bahan pilihan seperti gula, sellulosa dan sejenis lignin, merubah sisa-sisa tumbuhan menjadi humus, menggabungkan bahan yang membusuk pada lapisan tanah bagian atas dan membentuk bahan organik dan bahan mineral tanah (Barnes, 1997).

Setiadi (1989) menyatakan bahwa peranan terpenting dari organisme tanah di dalam ekosistemnya adalah sebagai perombak bahan anorganik yang tersedia bagi tumbuhan hijau. Nutrisi tanaman yang berasal dari berbagai residu tanaman akan mengalami proses dekomposisi sehingga terbentuk humus sebagai sumber nutrisi bagi tanah. Dapat dikatakan bahwa peranan ini sangat penting dalam mempertahankan dinamika ekosistem alam.

Menurut Suhardjono (1997), beberapa jenis fauna permukaan tanah dapat digunakan sebagai petunjuk (indikator) terhadap kesuburan tanah atau keadaan tanah. Borror dkk., (1992) menyatakan bahwa fauna tanah memperbaiki sifat fisik tanah dan menambah kandungan bahan organiknya. Wallwork (1976) menambahkan bahwa fauna tanah juga berfungsi sebagai perombak material tanaman dan penghancur kayu.

Fauna tanah cukup baik sebagai bioindikator tanah karena memiliki respon yang sensitif terhadap praktek pengelolaan lahan dan iklim, berkorelasi baik terhadap sifat tanah yang menguntungkan dan fungsi ekologis seperti penyimpanan air, dekomposisi dan siklus hara, netralisasi bahan beracun dan penekanan organisme patogen dan berbahaya. Fauna tanah juga dapat menggambarkan rantai sebab akibat yang menghubungkan keputusan pengelolaan lahan terhadap produktivitas akhir dan 
kesehatan tanaman dan hewan (Doran dan Zeiss, 2000).

Fauna tanah memiliki keuntungan jika digunakan sebagai bioindikator tanah, karena satu atau dua tingkat lebih tinggi dalam rantai makanan, dimana mereka berperan sebagai pemadu sifat kimia dan biologi yang berhubungan dengan sumber makanannya. Waktu regenerasi fauna tanah lebih panjang (hari hingga tahun) dibanding mikrobia metabolik aktif lainnya (jam hingga hari), sehingga membuat mereka lebih stabil dan tidak mudah berfluktuasi akibat perubahan hara yang sesaat dan tiba-tiba (Neher, 2001).

Fauna yang berpotensi sebagai bioindikator tanah yang mengandung sulfur tinggi adalah fauna yang hanya ditemukan di tempat yang berkadar sulfur tinggi. Fauna tanah yang hanya ditemukan di tempat yang berkadar sulfur tinggi (gunung Bromo) adalah Salticidae 3, Lycosidae 1, Lycosidae 2, Thomisidae dan Brachyderinae. Dari kelima famili tersebut yang mempunyai indeks nilai penting tertinggi adalah Brachyderinae, sehingga keberadaan famili ini dapat digunakan sebagai bioindikator tanah yang mengandung sulfur tinggi.

Fauna tanah yang hanya ditemukan di daerah Jemplang dan Penanjakan juga dapat digunakan sebagai indikator tanah yang mengandung sulfur tinggi. Hal ini disebabkan oleh kemampuan fauna tersebut untuk beradaptasi terhadap keberadaan sulfur rendah, sehingga tidak mampu bertahan pada kondisi yang mengandung sulfur tinggi. Pada pengamatan diperoleh 6 famili fauna yang tidak ditemukan di daerah Bromo, yaitu: Opiliones 1, Opiliones 2, Lathriidae, Meloidae, Mesoveliidae dan Mantispidae. Famili Mesoveliidae dapat digunakan sebagai bioindikator keberadaan tanah yang mengandung sulfur tinggi, karena mempunyai indeks nilai penting tertinggi di kedua lahan dibandingkan enam famili lainnya.

Pearson (1994) menyatakan bahwa suatu jenis organisme dapat digunakan sebagai bioindikator jika memenuhi kriteria, yaitu secara taksonomi telah stabil dan cukup diketahui, sejarah alamiahnya diketahui, siap dan mudah disurvei dan dimanipulasi, taksa yang lebih tinggi terdistribusi secara luas pada berbagai tipe habitat, taksa yang lebih rendah spesialist dan sensitif terhadap perubahan habitat, pola keanekaragaman mengambarkan atau terkait dengan taksa lainnya yang berkerabat atau tidak dan memiliki potensi ekonomi yang penting.

Spesies yang range status ekologinya luas (spesifitasnya rendah) untuk keperluan monitoring perubahan lingkungan, lebih berguna sebagai indikator terhadap arah perubahan lingkungan dari pada spesies yang spesifitasnya tinggi (terbatas pada habitat tertentu). Spesies detektor, spesies yang spesifisitasnya sedang, lebih berguna untuk memantau perubahan, karena mereka memiliki tingkat preferensi yang berbeda terhadap suatu status ekologis. Perubahan relatif dari kelimpahannya sepanjang status ekologis mengindikasikan arah perubahan lingkungan yang terjadi. Spesies-spesies ini juga lebih rentan (vulnerable) dibandingkan dengan spesies indikator, karena variasi habitat atau status ekologis menyediakan sumber daya yang cocok bagi mereka (Shahabuddin, 2003).

\section{KESIMPULAN}

1. Fauna tanah yang ditemukan di Taman Nasional Bromo Tengger Semeru ada 10 ordo yang terdiri dari 29 famili, yaitu ordo Ordo Araneida 
Keanekaragaman Fauna Tanah Di Taman ...

(Famili Oxyopidae 1, Oxyopidae 2, Linyphiidae 1, Linyphiidae 2, Salticidae 1, Salticidae 2, Salticidae 3, Opiliones 1, Opiliones 2, Opiliones 3, Araneidae 1, Araneidae 2, Lycosidae 1, Lycosidae 2, Lycosidae 3 dan Thomisidae), Ordo Blattaria Famili Blattellidae, Ordo Coleoptera (Famili Scarabaeidae, Lathriidae, Meloidae dan Brachyderinae), Ordo Diptera (Famili Scapthophagidae dan Tachinidae), Ordo Hemiptera Famili Mesoveliidae, Ordo Homoptera Famili Hecalinae, Ordo Hymnoptera Famili Formicidae, Ordo Neuroptera Famili Mantispidae, Ordo Trichoptera Famili Limnephilidae dan Ordo Orthoptera Famili Acrididae.

2. Keanekaragaman fauna tanah di daerah gunung Bromo paling rendah jika dibandingkan daerah lainnya, dengan indeks keanekaragaman 2,07. Daerah Jemplang memiliki indeks keanekaragaman 2,35 dan daerah Penanjakan memiliki indeks keanekaragaman fauna tanah tertinggi, yaitu 2,73 .

3. Daerah gunung Bromo memiliki total Sulfur 74,683 mg/1000g tanah dan merupakan daerah penelitian dengan sulfur tertinggi. Fauna tanah yang dapat digunakan sebagai bioindikator tanah bersulfur tinggi adalah ordo Brachyderinae untuk indikator keberadaan fauna dan Mesoveliidae untuk bioindikator ketidakadaan fauna.

\section{E. UCAPAN TERIMAKASIH}

Penulis mengucapkan terima kasih kepada Lembaga penelitian dan pengembangan UIN maliki Malang yang telah mendanai penelitian ini.

\section{F. DAFTAR PUSTAKA}

Anonimous, 2009. Taman Nasional Bromo Tengger Semeru, http://www.dephut.go.id/INFORMA SI/TN\%20INDO-

ENGLISH/tn_bromo.htm, diakses 2 September 2009.

Barnes, B. V., Donald R. Z., Shirley R. D. and Stephen H. S. 1997. Forest Ecology. $4^{\text {th }}$ Edition. John Wiley and Sons Inc., New York.

Beare, M.H.D., Coleman, D.C., Crosley, D.A., Hendrix, P.F., and Odum, E.P. 1995. A Hirarchial Approach to Evaluating the Significance of Soil Biodiversity to Biogeochemical Cycling. J. Plant and Soil. 170.

Borror, D.J., Triplehorn, C.A., Johnson, N.F., 1996. Pengenalan Pelajaran Serangga, Edisi Keenam. Penerjemah Soetiyono Partosoejono. Gadjah Mada University Press, Yogyakarta.

Buckman, M.H dan Brady. 1982. Ilmu Tanah. Bharata Karya, Jakarta.

Doran, J. W and M. R. Zeiss. 2000. Soil Health and Sustainability: Managing the Biotic Component of Soil Quality. Aplied Soil Ecology (15). 3-11.

www.Elsevier.com/locate/apsoil.

Hidayat, S. dan Risna, R.A. 2007. Kajian Ekologi Tumbuhan Obat Langka di Taman Nasional Bromo Tengger Semeru. BIODIVERSITAS, Volume 8 Nomor 3 Juli 2007.

McGeoch, M. 1998. The Selection, Testing And Application of Terrestrial Insects as Bioindicators. Biological Reviews, 73.

Neher, D. A. 2001. Role of nematodes in soil health and their use as indicators. Journal of Nematology, 33 (4).

Pearson, D.L. 1994. Selecting Indicator Taxa For The Quantitative 
Assessment Of Biodiversity. Philosophical Transaction of the Royal Society of London, Series B : Biological Sciences, 345.

Rahmawaty. $2004 . \quad$ Studi Keanekaragaman Mesofauna Tanah Di Kawasan Hutan Wisata Alam Sibolangit (Desa Sibolangit, Kecamatan Sibolangit, Kabupaten aerah Tingkat II Deli Serdang, Propinsi Sumatera Utara). e-USU Repository.

Rizali, A., Buchori, D. dan Triwidodo, H. 2002. Keanekaragaman Serangga pada Lahan Persawahan-Tepian Hutan: Indikator untuk Kesehatan Lingkungan. Hayati, Volume 9 Nomor 2 Juni 2002.

Sarifuddin. 2004. Mikrobia sebagai Indikator Kesehatan Tanah, http://www.rudyct.com/PPS702ipb09145/sarifuddin.pdf dikunjungi 26 Oktober 2010.

Setiadi, Y. 1989. Pemanfaatan Mikro Organisme dalam Kehutanan.

Departemen Pendidikan dan Kebudayaan Direktorat Jenderal Pendidikan Tinggi Pusat Antara Universitas Bioteknologi. IPB, Bogor.

Shahabuddin. 2003. Pemanfaatan Serangga sebagai Bioindikator Kesehatan Hutan. http://repository.usu.ac.id/bitstream 123456789192592/Reference.pdf. dikunjungi 26 Oktober 2010.

Southwood, T.R.E. 1978. Ecological Methods. Second Edition. Chapman and Hall., New York.

Speight M.R., and Wylie, F.R. 2001. Insect Pests in Tropical Forestry. CABI Publishing.

Sugianto, A. 1994. Ekologi Kuanttatif. Penerbit Usaha Nasional, Surabaya.

Suhardjono, Y. R. 1997. Perbedaan Lima Macam Larutan yang Digunakan dalam Perangkap
Sumuran pada Pengumpulan Serangga Permukaan Tanah. Prosiding Seminar Biologi XV. Perhimpunan Biologi Indonesia Cabang Lampung dan Universitas Lampung. Lampung.

Suharto, Wagiyana dan Zulkarnain R. 2005. Survei Kupu-Kupu (Rhopalocera: Lepidoptera) di Hutan Ireng-Ireng Taman Nasional Bromo Tengger Semeru, Jurnal ILMU DASAR Vol. 6 No. 1, 2005.

Suin, N. M. 1997. Ekologi Fauna Tanah. Bumi Aksara, Jakarta.

Suwondo. 2002. Komposisi dan Keanekaragaman Mikroartropoda Tanah Sebagai Bioindikator Karakteristik Biologi Pada Tanah Gambut. Program studi Biologi PMIPA, FKIP, Universitas Riau.

Suwondo, Tandjung, S.D. dan Harminanani, S.D.T. 1996. Komposisi dan keanekaragaman Mikroartropoda tanah sebagai bioindikator deposisi asam di sekitar kawah Sikidang dataran tinggi Dieng Jawa Tengah. J. Berkala Pasca Sarjana UGM, Yogyakarta.

Wallwork, J. A. 1976. The Diversity and Distribution of Soil Fauna. Acad Press., London. 